\title{
PREFACE
}

\section{Preface for 50th anniversary}

\section{Michiaki Unno ${ }^{1}$}

Published online: 3 December 2019

(c) Springer Nature Singapore Pte Ltd. 2019

Surgery Today, the official English Journal of Japan Surgical Society, was first published in 1972, as "The Japanese Journal of Surgery". There are many journals published in English in Japan, but Surgery Today is the only journal of general surgery. This year is the 50th anniversary of the inception of Surgery Today in 1972. On behalf of the members of the Japan Surgical Society, I would like to express gratitude to all who have been involved in its publication, review, and editorial process.

The Japan Surgical Society was founded in 1899, making it one of the oldest medical societies in Japan. In 1900, we established a native language journal named "Nihon Geka Gakkai Zasshi", which is one of the longest running medical journals in Japan. To promote the internationalization of our society, we began publishing the English language journal named "The Japanese Journal of Surgery" in 1971 and changed its name to "Surgery Today" in 1992. Table 1

Table 1 Editors-in-chief of Surgery Today 1992-2019

\begin{tabular}{ll}
\hline Year & Name \\
\hline $1970-1986$ & Kiyoshi Inokuchi \\
$1987-1988$ & Takao Hattori \\
$1986-1993$ & Yoshio Mishima \\
$1994-1997$ & Keizo Sugimachi \\
$1998-1999$ & Seiki Matsuno \\
$2000-2005$ & Morito Monden \\
$2006-2007$ & Masao Tanaka \\
$2008-2011$ & Yoshihiko Maehara \\
$2012-2014$ & Yoshiki Sawa \\
$2014-2017$ & Yuichiro Doki \\
$2017-$ now & Michiaki Unno \\
\hline
\end{tabular}

Michiaki Unno

m_unno@surg.med.tohoku.ac.jp

1 Tohoku University Graduate School of Medicine, Sendai, Japan lists the names of the editors-in-chief of Surgery Today from the date of its inception.

The main purpose of Surgery Today is to provide a journal for the publication of high-quality papers documenting recent advances and new developments in all fields of surgery, both clinical and basic research. The journal welcomes original papers, review articles, short communications, and short technical reports ("How to do it"). Vol. 48, published in 2018 contains 148 articles in 1103 pages: 13 review articles, 115 original articles, 7 "how to do it" articles, and 13 other articles. The acceptance rate in 2018 was $17.4 \%$.

Improvement of the impact factor (IF) has always been strong desire. In 2009, the IF exceeded 1.0 for the first time, and the current IF is 2.077. According to InCites Journal Citation Reports, Surgery Today is ranked 87th of 203 surgical journals. We will continue to publish excellent papers, which will raise the IF further.

I believe that the ongoing publication of important papers in Surgery Today will contribute to social welfare, give the readers broad insights, and facilitate future progress over next 50 years. 


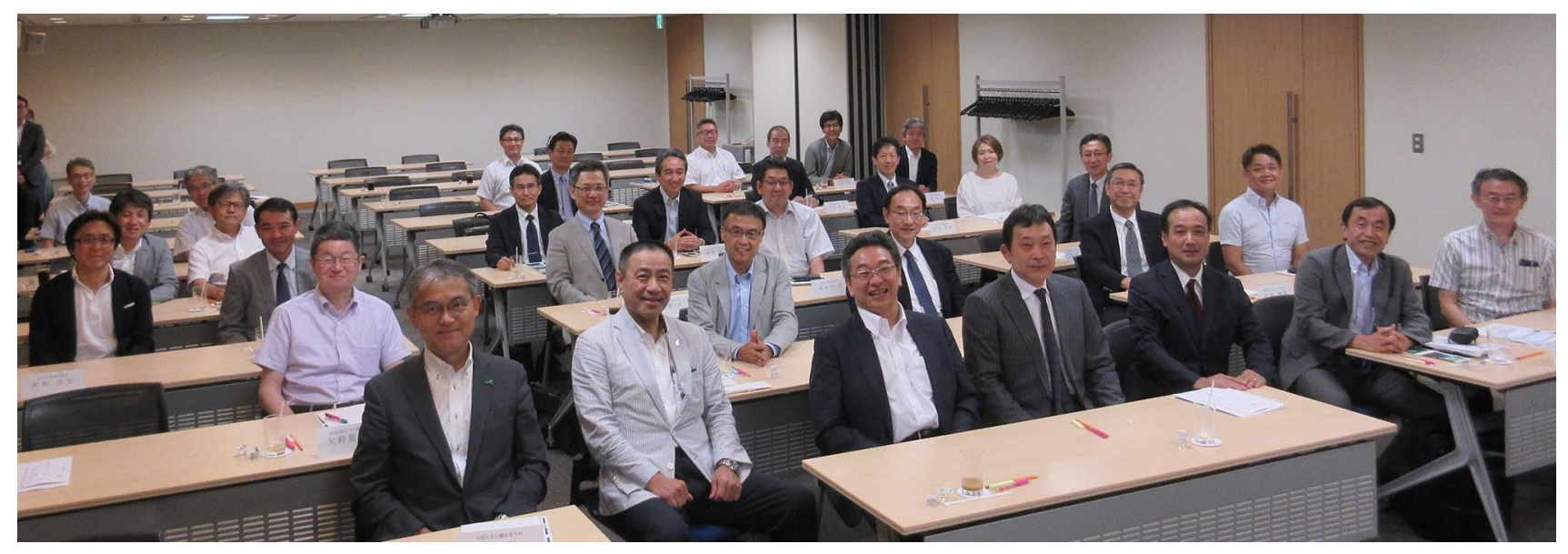

Legend of photo: Editorial board members (Photographed on August 8, 2019).

Publisher's Note Springer Nature remains neutral with regard to jurisdictional claims in published maps and institutional affiliations. 